Pacific Journal of Mathematics

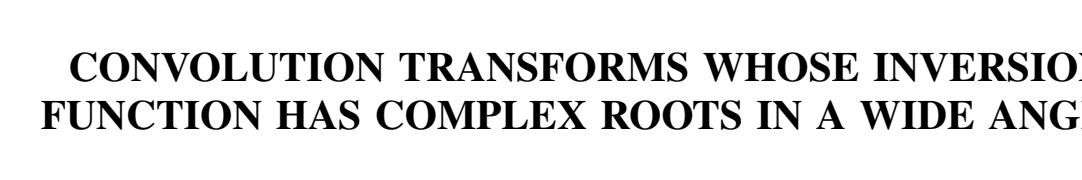




\section{CONVOLUTION TRANSFORMS WHOSE INVERSION FUNCTION HAS COMPLEX ROOTS IN A WIDE ANGLE}

\section{Zeev Ditzian}

In this paper a class of convolution transforms:

$$
f(x)=\int_{-\infty}^{\infty} G(x-t) \varphi(t) d t
$$

whose kernels $G(t)$ satisfy

$$
G(t)=\frac{1}{2 \pi i} \int_{-i \infty}^{i \infty}[E(s)]^{-1} \cdot e^{s t} d s
$$

where

$$
E(s)=\prod_{k=1}^{\infty}\left(1-s / a_{k}\right) \quad \text { or } \quad E(s)=\prod_{k=1}^{\infty}\left(1-s / a_{k}\right) \exp \left(s \operatorname{Re} a_{k}^{-1}\right)
$$

will be treated. Investigation of properties will be carried for the subclass defined by the restriction on $a_{k}$ as follows:

(a) For some $\psi, 0<\psi<\pi / 2$

$$
\min _{n=0,1,2}\left|n \pi-\arg a_{k}\right| \leqq \psi \quad \text { where } \quad a_{k} \neq 0 .
$$

(b) For some $0<q<1$

and integer $l \quad\left|a_{k+l}\right| \geqq q^{-1}\left|a_{k}\right|$ for all $k \geqq k_{0}$.

It should be mentioned that the restriction (a) on the argument of $a_{k}$ is much weaker than those used in other subclasses of convolution transforms defined by (1.1), (1.2) and (1.3) that were investigated before.

I. I. Hirschman and D. V. Widder [4] treated a class of transforms for which $\arg a_{k}$ tend to either 0 or $\pi$. J. Dauns and D. V. Widder [1] and the author [2] studied the case $E(s)=\prod_{k=1}^{\infty}\left(1-s^{2} / a_{k}^{2}\right)$ for which $\left|\arg a_{k}\right| \leqq \psi<\pi / 4$, that is: The sequence of roots contains pairs of $a_{k}$ and $-a_{k}$. A milder way of coupling was introduced by the author [3]. The question that arises is: Can we relax the restriction on the argument of the $a_{k}$ 's and still have the transforms and their inversion formulae? Of course it was shown [1, p. 442] that in some simple cases the analogous inversion formula to that of Hirschman and Widder does not hold. Examples can be given to show that in some cases (1.2) does not converge. Here a restriction on the growth of the roots is given (b) which assures us of the convergence of (1.2) and helps us to prove that 


$$
\lim _{m \rightarrow \infty} P_{m}(D) f(x)=\prod_{k=1}^{\infty}\left(1-a_{k}^{-1} D\right) f(x)=\varphi(x) \text { a.e. }
$$

where

$$
D \equiv \frac{d}{d x}
$$

We shall assume for convenience that $\left|a_{k}\right| \leqq\left|a_{k+1}\right|$ and also that $E(s)=\prod_{k=1}^{\infty}\left(1-s / a_{k}\right) \quad$ since treating $E(s)=\prod_{k=1}^{\infty}\left(1-s / a_{k}\right) \exp \left(s \operatorname{Re} a_{k}^{-1}\right)$ would mean only shifting the argument $t$ of $G(t)$ by the number $\sum \operatorname{Re} a_{k}^{-1}$.

It should be noted that the harder part of the proof is an estimate of $E(s)(\S 2)$ and an estimate on $\left|G_{m}(t)\right|=\left|P_{m}(D) G(t)\right|$ (in $\S 4$ ) the results achieved for the later had not been published for the nonvoid intersection of our class and the class of variation diminishing transforms.

\section{An estimate for $E(s)$.}

THEOREM 2.1. Suppose that $E(s)=\prod_{k=1}^{\infty}\left(1-s / a_{k}\right)$ and the sequence $\left\{a_{k}\right\}$ satisfies conditions (a) and (b) and let $0<\eta<\pi / 2-\psi$, then there exist $A(n)>0$ and $B(n)>0$ such that

$$
\left|E\left(r e^{i \theta}\right)\right| \geqq\left(A(n)+B(n) r^{2 n}\right)^{1 / 2}
$$

for any $n$ and $r$ uniformly for $\psi+\eta \leqq \theta \leqq \pi-\psi-\eta$ and $\pi+\psi+\eta \leqq \theta \leqq 2 \pi-\psi-\eta$.

Proof. Without loss of generality we may assume $\left|a_{k}\right| \leqq\left|a_{k+1}\right|$. We define $\varphi_{k}=\arg a_{k}$ and have

$$
\begin{aligned}
\mid 1- & r e^{i \theta} /\left.\left|a_{k}\right| e^{i \varphi k}\right|^{2}=1-2 \frac{r}{\left|a_{k}\right|} \cos \left(\theta-\varphi_{k}\right)+\frac{r^{2}}{\left|a_{k}\right|^{2}} \\
\geqq & 1-2 \frac{r}{\left|a_{k}\right|} \cos \eta+\frac{r^{2}}{\left|a_{k}\right|^{2}}=\left[1-\left(1+\frac{1}{2} \tan ^{2} \eta\right)^{-1}\right] \\
+ & {\left[\left(1+\frac{1}{2} \tan ^{2} \eta\right)^{-1}-2 \frac{r}{\left|a_{k}\right|} \cos \eta+\frac{r^{2}}{\left|a_{k}\right|^{2}} \cos ^{2} \eta\left(1+\frac{1}{2} \tan ^{2} \eta\right)\right] } \\
+ & \frac{1}{2} \frac{r^{2}}{\left|a_{k}\right|^{2}} \sin ^{2} \eta \geqq \frac{1}{2} \cdot \frac{\tan ^{2} \eta}{1+\frac{1}{2} \tan ^{2} \eta}+\frac{1}{2} \frac{r^{2}}{\left|a_{k}\right|^{2}} \sin ^{2} \eta .
\end{aligned}
$$

Therefore 


$$
\begin{aligned}
& \left.\prod_{k=1}^{n}\left(1-r e^{i \theta} / a_{k}\right)\right|^{2} \geqq\left(\left.\frac{\frac{1}{2} \tan ^{2} \eta}{1+\frac{1}{2} \tan ^{2} \eta}\right|^{n}\right. \\
& +\left(\frac{\sin ^{2} \eta}{2}\right)^{n} \frac{r^{2 n}}{\left|a_{1}\right|^{2} \cdots\left|a_{n}\right|^{2}} \equiv A_{1}(n)+B_{1}(n) r^{2 n} .
\end{aligned}
$$

To complete the proof it is enough to show that there exists a constant $c>0$ independent of $r$ and $\theta$ (in its specified angle) such that:

$$
\left|\prod_{n+1}^{\infty}\left(1-r e^{i \theta} / a_{k}\right)\right|^{2} \geqq c>0 .
$$

We shall write

$$
\begin{aligned}
& \prod_{k=n+1}^{\infty} \cdots=\left(\prod_{k=n+1}^{n_{1}(r)} \cdots\right) \cdot\left(\prod_{k=n_{1}(r)+1}^{n_{2}(r)} \cdots\right) \cdot\left(\prod_{k=n_{2}(r)+1}^{\infty} \cdots\right) \\
& \equiv I_{1}(r) \cdot I_{2}(r) \cdot I_{3}(r) .
\end{aligned}
$$

Choose $n_{1}(r)$ as the largest integer satisfying

$$
k \leqq n_{1}(r), \quad\left|a_{k}\right|<r / 2 \cos \eta .
$$

If $n_{1}(r)<n+1$ then $I_{1}(r)=1$; otherwise

$$
I_{1}(r)=\left|\prod_{k=n+1}^{n_{1}(r)}\left(1-r e^{i \theta} / a_{k}\right)\right|^{2} \geqq \prod_{k=n+1}^{n_{1}(r)}\left(1-\frac{2 r}{\left|a_{k}\right|} \cos \eta+\frac{r^{2}}{\left|a_{k}\right|^{2}}\right) \geqq 1 .
$$

We choose $n_{2}(r)$ as $n_{2}(r)=\min \{l: l \geqq n+1, k>l \quad$ implise $\left.\left|a_{k}\right|>4 r \cos \eta\right\}$ and therefore have

$$
I_{3}(r) \geqq \prod_{k=n_{2}(r)+1}^{\infty}\left(1-2 \frac{r}{\left|a_{k}\right|} \cos \eta+\frac{r^{2}}{\left|a_{k}\right|^{2}} \geqq \prod_{k=n_{2}(r)+1}^{\infty}\left(1-2 \frac{r}{\left|a_{k}\right|} \cos \eta\right) .\right.
$$

Using condition (b) and the definition of $n_{2}(r)$ we obtain

$$
I_{3}(r) \geqq \prod_{n=0}^{\infty}\left(1-\frac{1}{2} q^{n}\right)^{l}=c_{1}(q)>0 \quad \text { for } \quad 0<q<1 .
$$

We shall estimate $I_{2}(r)$ by (2.2) as follows

$$
\begin{aligned}
I_{2}(r) & \geqq \prod_{k=n_{1}(r)+1}^{n_{2}(r)}\left(\frac{1}{2} \frac{\tan ^{2} \eta}{1+\frac{1}{2} \tan ^{2} \eta}+\frac{r^{2}}{\left|a_{k}\right|^{2}} \cdot \frac{\sin ^{2} \eta}{2}\right) \\
& \geqq\left(\frac{1}{2} \frac{\tan ^{2} \eta}{1+\frac{1}{2} \tan ^{2} \eta}\right)^{n_{2}(r)-n_{1}(r)-1}
\end{aligned}
$$


(if $n_{1}(r)<n+1$ then instead of $n_{2}(r)-n_{1}(r)-1$ we should write $\left.n_{2}(r)-n-1\right)$. We can estimate $n_{2}(r)-n_{1}(r)-1$ from above as follows; we shall find the smallest $m$ satisfying $q^{-m}>4 r \cos \eta / r(2 \cos \eta)^{-1}=$ $8 \cos ^{2} \eta$ which we call $m_{0}$, by (b) $m_{0} \cdot l>n_{2}(r)-n_{1}(r)$.

Combining these results

$$
\begin{aligned}
\mid \prod_{k=n+1}^{\infty} & \left.\left(1-r e^{i \theta} / a_{k}\right)\right|^{-2}=I_{1}(r) \cdot I_{2}(r) I_{3}(r) \\
& \geqq \prod_{n=1}^{\infty}\left(1-\frac{1}{2} q^{n}\right)^{l} \cdot\left(\frac{1}{2} \frac{\tan ^{2} \eta}{1+\frac{1}{2} \tan ^{2} \eta}\right)^{m_{0} \cdot l}=c>0 .
\end{aligned}
$$

COROLLARY 2.1.a. Under assumptions (a) and (b) the kernel function $G(t)$ satisfies

$$
E(s)^{-1}=\int_{-\infty}^{\infty} e^{-s t} G(t) d t
$$

$G(t) \in C^{\infty}(-\infty, \infty)$ and

$$
G^{(n)}(t)=\frac{1}{2 \pi i} \int_{-i \infty}^{i \infty} \frac{s^{n} e^{s t} d s}{E(s)} .
$$

REMARK 2.1.b. In Theorem 2.1 it is shown that if (a) and (b) are satisfied then for $0<\eta<\pi / 2-\psi$

$$
\left|E\left(r e^{i \theta}\right)\right| \geqq C(q, \eta)
$$

for

$$
\left\{\theta:\left|\theta-\frac{\pi}{2}\right|<\frac{\pi}{2}-\psi-\eta\right\} \cup\left\{\theta:\left|\theta-\frac{3 \pi}{2}\right|<\frac{\pi}{2}-\psi-\eta\right\}
$$

and $C(q, \eta)$ does not depend on $r$ or the smallest $\left|a_{k}\right|$.

3. Asymptotic estimate of $G(t)$. Define $\alpha_{1}$ and $\alpha_{2}$ by:

$$
\begin{aligned}
& \alpha_{1}=\max \left\{\operatorname{Re} a_{k},-\infty \mid \operatorname{Re} a_{k}<0\right\} \quad \text { and } \\
& \alpha_{2}=\min \left\{\operatorname{Re} a_{k}, \infty \mid \operatorname{Re} a_{k}>0\right\} .
\end{aligned}
$$

THEOREM 3.1. Suppose $E(s)=\prod_{k=1}^{\infty}\left(1-s / a_{k}\right)$, the sequence $\left\{a_{k}\right\}$ satisfies conditions (a) and (b) and let $G(t)$ be defined by (1.2), then:

(i) $\alpha_{1}=-\infty$ implies

$$
G^{(n)}(t)=o\left(e^{c t}\right)
$$

for all $c, c<0$. 
(ii) $\alpha_{1}>-\infty$ implies

$$
G^{(n)}(t)=\sum_{l=1}^{L} P_{l}(t) \exp \left(a_{k(l)} t\right)+o\left(e^{c t}\right) \quad t \rightarrow \infty
$$

where $\operatorname{Re} a_{k(l)}=\alpha_{1} 1 \leqq l \leqq L\left(a_{k(j)} \neq a_{k(i)}\right.$ for $i \neq j$ and if $a_{k} \neq a_{k(l)}$ $1 \leqq l \leqq L$ then $\left.\operatorname{Re} a_{k} \neq \alpha_{1}\right) P_{l}(t)$ are polynomials of degree $\mu_{l}$ where $\mu_{l}+1$ is the multiplicity of $a_{k(l)}$ in $\left\{a_{k}\right\}$ and $c<\alpha_{1}$.

(iii) $\alpha_{2}=\infty$ implies

$$
G^{(n)}(t)=o\left(e^{c t}\right) \text { for all } c, c>0 .
$$

(iv) $\alpha_{1}<\infty$ implies

$$
G^{(n)}(t)=\sum_{l=L+1}^{L+M} P_{l}(t) \exp \left(a_{k(l)} t\right)+o\left(e^{c t}\right) \quad t \rightarrow-\infty
$$

where $\operatorname{Re} a_{k(l)}=\alpha_{2}$ for $L+1 \leqq l \leqq L+M, P_{l}(t)$ are as in (b) and $c>\alpha_{2}$.

Proof. The proof follows the well established method of Hirschman and Widder [5, p. 108]. In order to use this method it is enough to show that

$$
|E(\sigma+i \tau)|^{-1}=0\left(|\tau|^{-n}\right)
$$$$
|\tau| \rightarrow \infty
$$

uniformly for $-A \leqq \sigma<A$ for every finite $A$. By Theorem 2.1 we have for $|\tau| /|\sigma|>\tan (\psi+\eta)$ and therefore for $|\tau|>A \tan (\psi+\eta)$ (where $\eta>0 \psi+\eta<\pi / 2$ and $\psi$ is defined in condition (a))

$$
|E(\sigma+i \tau)|^{-1} \leqq\left(A(n)+B(n)|\sigma+i \tau|^{2 n}\right)^{-1 / 2} \leqq B(n)^{-1 / 2}|\tau|^{-n} .
$$

4. $G_{m}(t)$ and properties. Define $G_{m}(t)$ by

$$
E_{m}(s)^{-1}=\int_{-\infty}^{\infty} e^{-s t} G_{m}(t) d t
$$

where

$$
E_{m}(s)=\prod_{k=m+1}^{\infty}\left(1-s / a_{k}\right) \text {. }
$$

By Theorem 2.1 and Corollary 2.1.a we have $G_{m}(t) \in C^{\infty}(-\infty,-\infty)$ and for $m=0,1,2, \cdots$

$$
G_{m}^{(n)}(t)=\frac{1}{2 \pi i} \int_{-i \infty}^{i \infty} \frac{s^{n} e^{s t}}{E_{m}(s)} d s
$$

The asymptotic estimates of Theorem 3.1 for $G_{m}(t)$ that satisfies condition (a) and (b) will be useful; however the following new estimate will be essential for the proof of the inversion formula. 
THEOREM 4.1. Let conditions (a) and (b) hold and $\left|a_{k}\right| \leqq\left|a_{k+1}\right|$, then

$$
\begin{aligned}
\left|G_{m}(t)\right| & \leqq M_{1}\left|a_{m+1}\right| \exp \left(-\frac{1}{2} \cos \psi\left|a_{m+1} t\right|\right) \\
& +M_{2}\left|a_{m+2}\right| \exp \left(-\frac{1}{2} \cos \psi\left|a_{m+2} t\right|\right)
\end{aligned}
$$

Proof. We shall divide the proof of (4.4) into two cases

(I) $\left|a_{m+2}\right| \leqq 4\left|a_{m+1}\right| / \cos \psi$

(II) $\left|a_{m+2}\right| \geqq 4\left|a_{m+1}\right| / \cos \psi$.

To show (4.4) in Case I we write $d_{m}=1 / 2 \cos \psi\left|a_{m+1}\right|$ and since $d_{m}<\left|a_{m+1}\right| \cos \psi$ we have

$$
G_{m}(t)=\frac{1}{2 \pi i} \int_{d_{m}-i \infty}^{d_{m}+i \infty} \frac{e^{s t}}{E_{m}(s)} d s=\frac{1}{2 \pi i} \int_{-d_{m}-i \infty}^{-d_{m}+i \infty} \frac{e^{s t}}{E_{m}(s)} d s .
$$

Using the first integral we have

$$
\left|G_{m}(t)\right| \leqq \frac{1}{2 \pi} e^{d m^{t}} \int_{-\infty}^{\infty}\left|E_{m}\left(d_{m}+i \tau\right)\right|^{-1} d \tau
$$

To estimate $G_{m}(t)$ we have to estimate $E_{m}\left(d_{m}+i \tau\right)$

$$
\begin{aligned}
& \left|E_{m}\left(d_{m}+i \tau\right)\right|=\prod_{i=1}^{2} \frac{1}{\left|a_{m+i}\right|}\left|a_{m+i}-d_{m}-i \tau\right| \cdot \prod_{k=m+3}^{\infty}\left|1-\frac{d_{m}+i \tau}{a_{k}}\right| \\
& \equiv I_{1}(\tau) \cdot I_{2}(\tau) \\
& \left|a_{m+i}\right|^{-2}\left|a_{m+i}-d_{m}-i \tau\right|^{2} \\
& =\left(\operatorname{Re} a_{m+i}-d_{m}\right)^{2}\left|a_{m+i}\right|^{-2}+\left(\tau-\operatorname{Im} a_{m+i}\right)^{2}\left|a_{m+i}\right|^{-2}
\end{aligned}
$$

$$
\begin{aligned}
& \geqq \frac{1}{4} \cos ^{2} \psi+\left(\tau^{2}-2 \tau \operatorname{Im} a_{m+i}+\left(\operatorname{Im} a_{m+i}\right)^{2}\right)\left|a_{m+i}\right|^{-2} \\
& \geqq \frac{1}{8} \cos ^{2} \psi+\frac{1}{8} \frac{\cot ^{2} \psi}{1+\frac{1}{8} \cot ^{2} \psi} \tau^{2}\left|a_{m+i}\right|^{-2} \\
& +\left(\left[1+\frac{1}{8} \cot ^{2} \psi\right]^{-1} \tau^{2}-2 \tau \operatorname{Im} a_{m+i}\right. \\
& \left.+\left(1+\frac{1}{8} \cot ^{2} \psi\right)\left(\operatorname{Im} a_{m+i}\right)^{2}\right)\left|a_{m+1}\right|^{-2} \geqq A(\psi)+B(\psi) \tau^{2}\left|a_{m+i}\right|^{-2}
\end{aligned}
$$

where $A(\psi)=1 / 8 \cos ^{2} \psi$ and

$$
B(\psi)=\frac{1}{8} \frac{\cot ^{2} \psi}{1+\frac{1}{8} \cot ^{2} \psi} .
$$


Using (4.7) and since $\left|a_{m+2}\right| \geqq\left|a_{m+1}\right|$

$$
\begin{aligned}
I_{1}(\tau) & \geqq\left\{A(\psi)^{2}+2 A(\psi) B(\psi)\left|a_{m+2}\right|^{-2} \tau^{2}+B(\psi)^{2}\left|a_{m+2}\right|^{-4} \tau^{4}\right\}^{1 / 2} \\
& \geqq k_{1}\left(1+\tau^{2}\left|a_{m+1}\right|^{-2}\right) .
\end{aligned}
$$

To estimate $I_{2}(\tau)$ we recall from Remark 2.1.b that when $d_{m}+i \tau=r e^{i \theta}$ and $\psi+\eta \leqq \theta \leqq 2 / \pi$ or $3 \pi / 2 \leqq \theta \leqq 2 \pi-\psi-\eta$, that is when $|\tau| \geqq d_{m} \tan (\psi+\eta), I_{2}(\tau) \geqq c>0$.

When $|\tau| \leqq d_{m} \tan (\psi+\eta)$ we choose $n_{1} \geqq m+3$ such that $\left|a_{n_{1}}\right| \geqq$ $2 d_{m}(1+\tan (\psi+\eta))$ and therefore

$$
\begin{aligned}
I_{2}(\tau) & \geqq\left\{\prod_{k=m+3}^{n_{1}} A(\psi)\right\}^{\frac{1}{2}} \cdot \prod_{k=n_{1}+1}^{\infty}\left(1-\frac{d_{m}(1+\tan (\psi+\eta))}{\left|a_{k}\right|}\right) \\
& \geqq A(\psi)^{\left(n_{1}-m-3\right) / 2} \cdot \prod_{n=0}^{\infty}\left(1-\frac{1}{2} q^{n}\right)^{l}
\end{aligned}
$$

and since by condition (b) $n_{1}-m-3$ is bounded regardless of $m$ $I_{2}(\tau) \geqq c_{1}$.

Therefore (4.6) and (4.7) yield

$$
\begin{aligned}
\left|G_{m}(t)\right| & \leqq C_{2} e^{d_{m} t} \int_{-\infty}^{\infty}\left[1+\left|a_{m+1}\right|^{-2} \tau^{2}\right]^{-1} d \tau \\
& \leqq M_{1}\left|a_{m+1}\right| \exp \left(\frac{1}{2} \cos \psi\left|a_{m+1}\right| t\right) .
\end{aligned}
$$

This estimation though correct for all $t$ is valuable only for $t \leqq 0$; for $t \geqq 0$ we obtain the result taking the second integral of (4.5) into consideration.

In the Case II, $\left|a_{m+2}\right|>4\left|a_{m+1}\right| / \cos \psi$, therefore

$$
\left|\operatorname{Re} a_{m+1}\right| \leqq\left|a_{m+1}\right|<\frac{1}{4}\left|\operatorname{Re} a_{m+2}\right| \text {. }
$$

To prove our result for $t \leqq 0$ we use the method of Theorem 3.1 and obtain

$$
G_{m}(t)=a_{m+1} \frac{e^{a_{m+1}}}{E_{m+1}\left(a_{m+1}\right)}+\int_{k_{m}-i \infty}^{k_{m}+i \infty} \frac{e^{s t} d s}{E_{m}(s)}
$$

when $\operatorname{Re} a_{m+1}<0$ and

$$
G_{m}(t)=\int_{k_{m}-i \infty}^{k_{m}+i \infty} \frac{e^{s t} d s}{E_{m}(s)}
$$

when $\operatorname{Re} a_{m+1}>0$; where $k_{m}=1 / 2\left|a_{m+2}\right| \cos \psi$.

Using (4.8) and (4.9) we obtain 


$$
\begin{gathered}
\left|G_{m}(t) \leqq\right| a_{m+1} \mid \cdot \frac{e^{\left|\operatorname{Re} a_{m+1}\right| t}}{E_{m+1}\left(a_{m+1}\right)}+e^{k_{m} t} \int_{-\infty}^{\infty}\left[E_{m}\left(k_{m}+i \tau\right)\right]^{-1} d \tau \\
\left|E_{m+1}\left(a_{m+1}\right)\right| \geqq \prod_{k=2}^{\infty}\left(1-\left|\frac{a_{m+1}}{a_{m+k}}\right|\right) \geqq \prod_{n=0}^{\infty}\left(1-\frac{1}{2} q^{n}\right)^{\imath} .
\end{gathered}
$$

Considerations already used in this theorem show that

$$
\left|E_{m+2}\left(k_{m}+i \tau\right)\right| \geqq C>0 \text {. }
$$

Since $\left|a_{m+1}\right| \leqq\left|a_{m+2}\right|$ and $\left|\operatorname{Re} a_{m+1}-k_{m}\right| \geqq 1 / 2 k_{m}>\left|a_{m+1}\right|$ we have

$$
\left|1-\frac{k_{m}+i \tau}{a_{m+1}}\right| \cdot\left|1-\frac{k_{m}+i \tau}{a_{m+2}}\right| \geqq\left(A(\psi)+B(\psi) \tau^{2}\left|a_{m+2}\right|^{-2}\right) .
$$

Recalling that

$$
E_{m}\left(k_{m}+i \tau\right)=E_{m+2}\left(k_{m}+i \tau\right) \cdot\left(1-\frac{k_{m}+i \tau}{a_{m+1}}\right)\left(1-\frac{k_{m}+i \tau}{a_{m+2}}\right)
$$

the proof of Case II for $t \leqq 0$ follows immediately. The proof when $t \geqq 0$ is similar taking $-k_{m}$ instead of $k_{m}$.

THEOREM 4.2. If conditions (a) and (b) are satisfied and $\left|a_{k}\right| \leqq$ $\left|a_{k+1}\right|$, then

$$
\left|G_{m}^{\prime}(t)\right| \leqq \sum_{i=1}^{3} N_{i}\left|a_{m+i}\right|^{2} \exp \left(-\frac{1}{2} \cos \psi\left|a_{m+i} t\right|\right) .
$$

Proof. Since $\left(1-a_{k}^{-1} D\right) G_{m}(t)=G_{m+1}(t)$ we have

$$
G_{m}^{\prime}(t)=-a_{m+1} G_{m+1}(t)+\left|a_{m+1}\right|\left|G_{m}(t)\right| \text {. }
$$

Using Theorem 4.1 for both $m$ and $m+1$ we obtain

$$
\begin{aligned}
& \left|G_{m}^{\prime}(t)\right| \leqq\left|a_{m+1}\right|\left|G_{m+1}(t)\right|+\left|a_{m+1}\right|\left|G_{m}(t)\right| \\
& \quad \leqq M_{1}\left|a_{m+1}\right|^{2} \exp \left(-\frac{1}{2} \cos \psi\left|a_{m+1} t\right|\right) \\
& +M_{2}\left|a_{m+1}\right|\left|a_{m+2}\right| \exp \left(-\frac{1}{2} \cos \psi\left|a_{m+2} t\right|\right) \\
& +M_{1}\left|a_{m+1}\right|\left|a_{m+2}\right| \exp \left(-\frac{1}{2} \cos \psi\left|a_{m+2} t\right|\right) \\
& +M_{2}\left|a_{m+1}\right|\left|a_{m+3}\right| \exp \left(-\frac{1}{2} \cos \psi\left|a_{m+3} t\right|\right)
\end{aligned}
$$

which yields (4.4) easily. 
REMARK 4.1.a. If in Theorems 4.1 and 4.2 the restriction, $\left|a_{m+1}\right|<$ $L\left|a_{m}\right|$ for some $L>1$, is added the proofs become obviously shorter and involve only the first term (in each theorem).

REMARK 4.1.b. It can be proved that if conditions (a) and (b) are satisfied and the multiplicity of $a_{m+1}$ and $a_{m+2}$ in $\left\{a_{k}\right\}$ is one then:

$$
\left|G_{m}(t)\right| \leqq M\left|a_{m+1}\right| \exp \left(-\left|\operatorname{Re} a_{m+1}\right||t|\right)
$$

and

$$
\begin{aligned}
\left|G_{m}^{\prime}(t)\right| & \leqq K\left|a_{m+1}\right|^{2} \exp \left(-\left|\operatorname{Re} a_{m+1}\right||t|\right) \\
& +N\left|a_{m+1}\right|\left|a_{m+2}\right| \exp \left(-\left|\operatorname{Re} a_{m+2}\right||t|\right) .
\end{aligned}
$$

These results are better than those of Theorem 4.1 and 4.2 but the proof I have uses those theorems. Since Theorems 4.1 and 4.2 are sufficient for the inversion result, I will not prove here these generalizations.

5. Inversion theorems. The results we shall obtain will correspond to the following two different situations: (1) Both $\alpha_{1}$ and $\alpha_{2}$ are finite. (2) Either $\alpha_{1}$ or $\alpha_{2}$ is non finite. $\left(\alpha_{1}\right.$ and $\alpha_{2}$ were defined in $\S 3$ ).

THEOREM 5.1. Suppose:

(1) Conditions (a) and (b) are satisfied.

(2) The constants $\alpha_{1}$ and $\alpha_{2}$ are finite, $\left|\int_{0}^{t} \varphi(v) d v\right| \leqq K e^{\left(\alpha_{2}-\varepsilon\right) t}$ for $t \geqq 0$ and $\left|\int_{t}^{0} \varphi(v) d v\right| \leqq K e^{\left(\alpha_{1}+\varepsilon\right) t}$ for $t \leqq 0$ for some $\varepsilon>0$, and $\varphi(t) \in L_{1}$ $(A, B)$ for all $A, B$ satisfying $-\infty<A<B<\infty$.

(3) At a point $x \int_{0}^{h}[\varphi(x+y)-\varphi(x)] d y=o(h) h \rightarrow 0$. Then

$$
\lim _{m \rightarrow \infty} P_{m}(D) f(x)=\varphi(x) \text {. }
$$

Proof. By Theorem 3.1 and assumption 2 we derive the uniform convergence in an interval $a \leqq x \leqq b$ of $\int_{-\infty}^{\infty} G^{(m)}(x-t) \varphi(t) d t$ and therefore

$$
\frac{d^{n}}{d x^{n}} f(x)=\int_{-\infty}^{\infty} G^{(n)}(x-t) \varphi(t) d t
$$

and

$$
P_{m}(D) f(x)=\int_{-\infty}^{\infty} G_{m}(x-t) \varphi(t) d t
$$


To complete the proof we remember that $\int_{-\infty}^{\infty} G_{m}(t) d t=1$ and therefore

$$
\begin{aligned}
& \left|P_{m}(D) f(x)-\varphi(x)\right|=\left|\int_{-\infty}^{\infty} G_{m}(x-t)[\varphi(t)-\varphi(x)] d t\right| \\
& =\left|\left\{\int_{-\infty}^{x-\delta}+\int_{x-\delta}^{x+\delta}+\int_{x+\delta}^{\infty}\right\} G_{m}^{\prime}(x-t) \alpha(t) d t\right|=I_{1}+I_{2}+I_{3}
\end{aligned}
$$

where $\alpha(t)$ is given by $\alpha(t)=\int_{x}^{t}[\varphi(v)-\varphi(x)] d v$. Using (3) one can choose $\delta$ so that for $(x-t) \leqq \delta|\alpha(t)| \leqq \varepsilon|x-t|$ and therefore

$$
\begin{aligned}
\left|I_{2}\right| & \leqq \varepsilon \int_{x-\delta}^{x+\delta}\left|G_{m}^{\prime}(x-t)\left\|x-t\left|d t=\varepsilon \int_{-\delta}^{\delta}\right| G_{m}^{\prime}(v)\right\| v\right| d v \\
& \leqq \varepsilon 2 \sum_{i=1}^{3} N_{i}\left|a_{m+i}\right|^{2} \cdot \int_{0}^{\delta} v \exp \left(-\frac{1}{2} \cos \psi\left|a_{m+i}\right| v\right) d v \\
& \leqq \varepsilon 2 \sum_{i=1}^{3} N_{i}\left\{\delta\left|a_{m+i}\right| \exp \left(-\frac{1}{2} \cos \psi\left|a_{m+i}\right| \delta\right) \cdot 2 \cdot(\cos \psi)^{-1}\right. \\
& \left.+4(\cos \psi)^{-2}\right\}
\end{aligned}
$$

For any fixed $\delta\left|a_{m+i}\right| \exp \left(-1 / 2 \cos \psi\left|a_{m+i}\right| \delta\right)=o(1) m \rightarrow \infty$. Using (2) $|\alpha(t)| \leqq K e^{\left(\alpha_{2}-\varepsilon\right) t}$ for $t \geqq 0$ and $|\alpha(t)| \leqq K e^{\left(\alpha_{1}+\varepsilon\right) t}$ for $t \leqq 0$ and therefore

$$
\begin{aligned}
\left|I_{3}\right| & \leqq K e^{\left(\alpha_{1}+\varepsilon\right)(x+\delta)} \int_{x+\delta}^{\max (x+\delta, 0)} \sum_{i=1}^{3} N_{i}\left|a_{m+i}\right|^{2} \exp \left(\frac{1}{2} \cos \psi\left|a_{m+i}\right| t\right) \\
& +\sum_{i=1}^{3} K N_{i}\left|a_{m+i}\right|^{2} \int_{\max (x+\delta, 0)}^{\infty} \exp \left(-\frac{1}{2} \cos \psi\left|a_{m+1}\right| t\right) e^{\left(\alpha_{2}-\delta\right) t} d t .
\end{aligned}
$$

Since $\lim _{x \rightarrow \infty} x e^{-a x}=0$ for $a>0$ we obtain $I_{3}=o(1) m \rightarrow \infty$ and similarly $I_{2}=o(1) m \rightarrow \infty$.

REMARK 5.1.a. Condition (2) can be replaced by a milder condition $\left(2^{*}\right)$ when there are only simple roots on $\operatorname{Re} z=\alpha_{1}$ and $\operatorname{Re} z=\alpha_{2}$. $\left(2^{*}\right)|\alpha(t)| \leqq K \chi(t) e^{\alpha_{2} t}$ for $t \leqq 0$ and $|\alpha(t)| \leqq K \chi(t) e^{\alpha_{1} t}$ for $t \geqq 0$ where $\chi(t)>0$ and $\int_{-\infty}^{\infty} \chi(t) d t<\infty$. In the proof the only change is in showing the uniform convergence (on a finite interval) of (5.2).

If for some $G(t) \alpha_{1}=-\infty$ then for $G^{*}(t), G^{*}(t) \equiv G(-t) \alpha_{2}=\infty$ and vice versa. We shall treat therefore such kernels for which $\alpha_{1}=-\infty$. For the inversion result we shall need the following lemma.

LEMmA. 5.2. If conditions (a) and (b) are satisfied and $\alpha_{1}=-\infty$, then $G(t)=0$ for $t \geqq 0$. 
Proof. Let $\left[1-s / a_{i}\right]^{-1}=\int_{-\infty}^{\infty} e^{-s t} g_{i}(t) d t$, then since $\operatorname{Re} a_{i}>0$

$$
g_{i}(t)= \begin{cases}a_{i} e^{a_{i} t} & t<0 \\ 0 & t>0\end{cases}
$$

Define $G_{m}^{*}(t)=g_{1} * g_{2} * \cdots * g_{m}(t)$, it is clear that $G_{m}^{*}(t)=0$ for $t>0$ (by induction) and that

$$
G_{m}^{*}(t)=\frac{1}{2 \pi i} \int_{-i \infty}^{i \infty} e^{s t}\left[\prod_{k=1}^{m}\left(1-\frac{s}{a_{k}}\right)\right]^{-1} d s .
$$

We have, for all $m$

$$
\begin{gathered}
G(t)=\int_{-\infty}^{\infty} G_{m}^{*}(v) G_{m}(t-v) d v=\int_{-\infty}^{0} G_{m}^{*}(v) G_{m}(t-v) d v \\
\left|G_{m}^{*}(t)\right| \leqq\left|g_{1}()\right| *\left|g_{2}()\right| * \cdots *\left|g_{m}(t)\right| \\
\quad=\prod_{i=1}^{m} \frac{\left|a_{i}\right|}{\operatorname{Re} a_{i}} h_{1} * \cdots * h_{m}(t)
\end{gathered}
$$

where

$$
h_{i}(t)=\left\{\begin{array}{ll}
\operatorname{Re} a_{i} \exp \left(\operatorname{Re} a_{i} t\right) & t<0 \\
0 & t>0
\end{array} .\right.
$$

It is well known that $\left|h_{1} * \cdots * h_{m}(t)\right| \leqq \min _{1<k \leqq m} \operatorname{Re} a_{k}$ (see [5, p. 138]) and that for $m \geqq m_{0} \min _{1<k \leqq m} \operatorname{Re} a_{k}=\alpha_{2}$. Therefore for $m \geqq m_{0}$

$$
\left|G_{m}^{*}(t)\right| \leqq \frac{\alpha_{2}}{\cos ^{m} \psi}\left(\left|a_{i}\right| \leqq(\cos \psi)^{-1}\left|\operatorname{Re} a_{i}\right|\right) .
$$

Since we have

$$
\begin{aligned}
|G(t)| & \leqq \alpha_{2} \cdot(\cos \psi)^{-m} \int_{-\infty}^{0}\left|G_{m}(t-v)\right| d v \\
& =\alpha_{2}(\cos \psi)^{-m} \cdot \int_{t}^{\infty}\left|G_{m}(v)\right| d v
\end{aligned}
$$

using Theorem 4.1 we obtain for $t>0$

$$
\begin{aligned}
|G(t)| & \leqq \alpha_{2}(\cos \psi)^{-m} \cdot 2(\cos \psi)^{-1}\left[M_{1} \exp \left(-\frac{1}{2} \cos \psi\left|a_{m+1}\right||t|\right)\right. \\
& \left.+M_{2} \exp \left(-\frac{1}{2} \cos \psi\left|a_{m+2}\right||t|\right)\right] .
\end{aligned}
$$

Condition (b) implies for every $t \neq 0$

$$
(\cos \psi)^{-m} \exp \left(-\frac{1}{2} \cos \psi\left|a_{m+i}\right||t|\right)=o(1) \quad m \rightarrow \infty
$$


for $i=1,2, \cdots$. Therefore $G(t)=o(1) m \rightarrow \infty$ for $t>0$ and being independent of $m G(t)=0$ for $t>0$. Since $G(t) \in C^{\infty}(-\infty, \infty) G(t)=0$ for $t=0$ also.

THEOREM 5.3. Suppose:

(1) Conditions (a) and (b) are satisfied.

(2) $\alpha_{1}=-\infty, \varphi(t)$ is defined for $t \geqq M$ and $\varphi(t) \in L_{1}(M, R)$ for all $R<\infty$ and $\int_{M}^{t} \varphi(t) d t \leqq K e^{\left(\alpha_{2}-\varepsilon\right) t}$.

(3) Conditions (3) of Theorem 5.1 is satisfied. Then for $x>M$

$$
\lim _{m \rightarrow \infty} P_{m}(D) f(x)=\varphi(x)
$$

Proof. The proof is almost identical to that of Theorem 5.1, but for the convergence of

$$
\int_{-\infty}^{\infty} G^{(n)}(x-t) \varphi(t) d t \text { and } \int_{-\infty}^{\infty} G_{m}(x-t) \varphi(t) d t
$$

we have to use also Lemma 5.2 (remembering that $G_{m}(t)$ satisfies also conditions (a) and (b) and $\alpha_{1}=-\infty$ and therefore $G_{m}(t)=0$ for $t \geqq 0$ ).

\section{REFERENCES}

1. J. Dauns and D. V. Widder, Convolution transforms whose inversion functions have complex roots, Pacific J. Math. (2) 15 (1965), 427-442.

2. Z. Ditzian, On asymptotic estimates for kernels of convolution transforms, Pacific J. Math. (2) 21 (1967), 249-254.

3. - On a class of convolution transforms, Pacific J. Math. 25 (1968), 83-107. 4. I. I. Hirschman and D. V. Widder, Convolution transforms with complex kernels, Pacific J. Math. 1 (1951), 211-225.

5. — The convolution transform, Princeton, 1955.

Received November 27, 1967. This work was partially supported by NRC grant A-4816. 


\section{PACIFIC JOURNAL OF MATHEMATICS}

\section{EDITORS}

\section{H. ROYDEN}

Stanford University

Stanford, California

\section{J. Dugundu}

Department of Mathematics University of Southern California Los Angeles, California 90007

RICHARD ARENS

University of California Los Angeles, California 90024

ASSOCIATE EDITORS
E. F. Beckenbach
B. H. NEUMANN
F. WoLF
K. YosidA

\section{SUPPORTING INSTITUTIONS}

\author{
UNIVERSITY OF BRITISH COLUMBIA \\ CALIFORNIA INSTITUTE OF TECHNOLOGY \\ UNIVERSITY OF CALIFORNIA \\ MONTANA STATE UNIVERSITY \\ UNIVERSITY OF NEVADA \\ NEW MEXICO STATE UNIVERSITY \\ OREGON STATE UNIVERSITY \\ UNIVERSITY OF OREGON \\ OSAKA UNIVERSITY \\ UNIVERSITY OF SOUTHERN CALIFORNIA
}

STANFORD UNIVERSITY

UNIVERSITY OF TOKYO

UNIVERSITY OF UTAH

WASHINGTON STATE UNIVERSITY

UNIVERSITY OF WASHINGTON

AMERICAN MATHEMATICAL SOCIETY
CHEVRON RESEARCH CORPORATION
TRW SYSTEMS

AMERICAN MATHEMATICAL SOCIETY

TRW SYSTEMS

NAVAL WEAPONS CENTER

Mathematical papers intended for publication in the Pacific Journal of Mathematics should be in typed form or offset-reproduced, double spaced with large margins. Underline Greek letters in red, German in green, and script in blue. The first paragraph or two must be capable of being used separately as a synopsis of the entire paper. It should not contain references to the bibliography. Manuscripts, in duplicate if possible, may be sent to any one of the four editors. All other communications to the editors should be addressed to the managing editor, Richard Arens, University of California, Los Angeles, California 90024.

Each author of each article receives 50 reprints free of charge; additional copies may be obtained at cost in multiples of 50 .

The Pacific Journal of Mathematics is published monthly. Effective with Volume 16 the price per volume (3 numbers) is $\$ 8.00$; single issues, $\$ 3.00$. Special price for current issues to individual faculty members of supporting institutions and to individual members of the American Mathematical Society: $\$ 4.00$ per volume; single issues $\$ 1.50$. Back numbers are available.

Subscriptions, orders for back numbers, and changes of address should be sent to Pacific Journal of Mathematics, 103 Highland Boulevard, Berkeley 8, California.

Printed at Kokusai Bunken Insatsusha (International Academic Printing Co., Ltd.), 7-17, Fujimi 2-chome, Chiyoda-ku, Tokyo, Japan.

PUBLISHED BY PACIFIC JOURNAL OF MATHEMATICS, A NON-PROFIT CORPORATION

The Supporting Institutions listed above contribute to the cost of publication of this Journal, but they are not owners of publishers and have no responsibility for its content or policies. 


\section{Pacific Journal of Mathematics \\ Vol. 27, No. 3}

March, 1968

Charles A. Akemann, Invariant subspaces of $C(G) \ldots \ldots \ldots \ldots \ldots \ldots . \ldots 41$

Dan Amir and Zvi Ziegler, Generalized convexity cones and their duals ... . 425

Raymond Balbes, On ( $J, M, \mathrm{~m})$-extensions of order sums of distributive

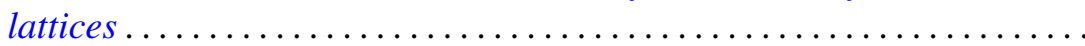

Jan-Erik Björk, Extensions of the maximal ideal space of a function algebra ........................................ 453

Frank Castagna, Sums of automorphisms of a primary abelian group ...... 463

Theodore Seio Chihara, On determinate Hamburger moment problems ..... .

Zeev Ditzian, Convolution transforms whose inversion function has complex

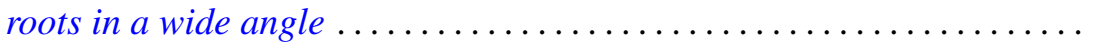

Myron Goldstein, On a paper of Rao .

Velmer B. Headley and Charles Andrew Swanson, Oscillation criteria for

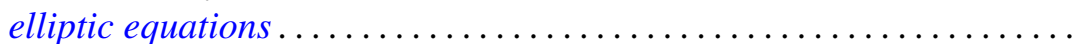

John Willard Heidel, Qualitative behavior of solutions of a third order nonlinear differential equation............................

Alan Carleton Hindmarsh, Pick's conditions and analyticity.............

Bruce Ansgar Jensen and Donald Wright Miller, Commutative semigroups

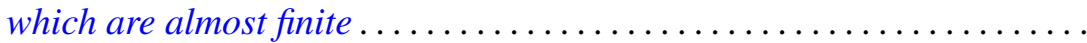

Lynn Clifford Kurtz and Don Harrell Tucker, An extended form of the

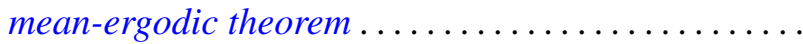

S. P. Lloyd, Feller boundary induced by a transition operator ...

Henry B. Mann, Josephine Mitchell and Lowell Schoenfeld, A new proof of the maximum principle for doubly-harmonic functions ...

Robert Einsohn Mosher, The product formula for the third obstruction ..

Sam Bernard Nadler, Jr., Sequences of contractions and fixed points ...

Eric Albert Nordgren, Invariant subspaces of a direct sum of weighted shifts...

Fred Richman, Thin abelian p-groups ...

Jordan Tobias Rosenbaum, Simultaneous interpolation in $\mathrm{H}_{2}$. II ...

Charles Thomas Scarborough, Minimal Urysohn spaces .

Malcolm Jay Sherman, Disjoint invariant subspaces..... .

Joel John Westman, Harmonic analysis on groupoids....

621

William Jennings Wickless, Quasi-isomorphism and TFM

Minoru Hasegawa, Correction to "On the convergence of resolvents of operators" 